\title{
NHS is not (yet) in crisis, but what about school rugby?
}

\author{
Fiona Godlee editor in chief, The BMJ
}

If a crisis is the point of judgment, the nadir, the turning point, the NHS in England can't yet be judged to be in crisis, said John Appleby of the health think tank the King's Fund in a BBC interview this week, because things may well get worse (doi:10. $1136 / \mathrm{bmj} . \mathrm{h} 50$ ). This is hardly reassuring but probably realistic. Hospitals around the country are declaring "major incidents" because of a lack of beds or staff or both, emergency departments report that they are at breaking point, and general practice is under unprecedented pressure (doi:10.1136/bmj.h66, doi:10.1136/bmj.g7266, doi:10.1136/bmj.g6069, doi:10.1136/ bmj.g6040). And there is little sign yet of things improving. Less realistic but more palatable is the belief of NHS England's chief executive, Simon Stevens, that the £30bn (funding gap expected for 2020-21 can be narrowed to $£ 8 \mathrm{bn}$. This is magical thinking, says Nigel Hawkes (doi:10.1136/bmj.g7842).

So what's the answer? In a new series of articles we are inviting commentators to say what they would do if they ruled the NHS. The first of these, last week, called for an end to the internal market (doi:10.1136/bmj.g7762). This week's prescription outlines a better future for diabetes care (doi:10.1136/bmj. g7848). In the build up to May's general election we also want to capture the experiences of people on the NHS frontline. If you'd like to take part please email voices@bmj.com.

One crucial voice on the NHS over the past 20 years has been Allyson Pollock. Unafraid of controversy, she is viewed by some as a Cassandra, constantly prophesying doom, and by others, myself included, as a courageous and meticulous commentator whose gloomy analysis that the NHS has become little more than a logo (doi:10.1136/bmj.329.7478.1349) may sadly be proved right in the coming months. While continuing to champion the NHS as a publicly funded and publicly provided service, Pollock recently turned her attention to rugby. Her book Tackling Rugby: What Every Parent Should Know About Injuries was published at the end of last year. Born of her own worrying experiences as a rugby mum, it documents her attempts to get information on the incidence and types of rugby injury among schoolchildren. She concludes that no single organisation is responsible for monitoring injuries, an important step in taking injury prevention seriously instead of accepting injury as just something that happens. This lack of monitoring has led to obfuscation, fragmentation, under-reporting, and misleading reassurances to parents and children. Her own research indicates that the burden of injury among children playing rugby is far heavier than previously thought.

And yet, as Pollock makes clear, this is not a new concern. At the end of her book she reproduces a letter, one of a series published in The BMJ more than 30 years ago, highlighting the failure of sporting bodies and government departments to monitor rugby injuries (BMJ 1977;2:118, doi:10.1136/bmj.2. 6079.118).

In response to the book we asked the paediatric neurosurgeon Michael Carter to give his views on the risks of school rugby. His clinical experience fits the picture outlined by Pollock: anecdotal accounts of serious injury that are sufficiently frequent to be worrying and which he and colleagues rarely encounter from other school sports. He reaches the same conclusion as Pollock: that there is a dire lack of any comprehensive, coordinated, national dataset of injuries and, even worse, a lack of the will to set one up. He says, "It is vital that schools, clubs, medical facilities, and, most importantly, regulatory bodies cooperate now to quantify the risks of school rugby" (doi:10. 1136/bmj.h26).

We may not yet be able to use the word crisis to describe the current state of the NHS, but let's call the current state of monitoring and prevention of rugby injury in schools what it is: a scandal. It needs urgent remedy before more children and their families suffer the consequences of collective neglect.

Cite this as: BMJ 2015;350:h78

๑ BMJ Publishing Group Ltd 2015 